\title{
A new technique for modeling neuronal connectivity using human pluripotent stem cells
}

\author{
Chun-Ting Lee*,1, Raphael M. Bendriem ${ }^{1}$ and William J. Freed ${ }^{2}$ \\ Cellular Neurobiology Research Branch, Intramural Research Program, National Institute on Drug Abuse, \\ National Institutes of Health, Baltimore, MD, USA
}

\begin{abstract}
.
Purpose: We describe a technique for independently differentiating neocortical and mesencephalic dopaminergic (mDA) neurons from a single human pluripotent stem cell (hPSC) line, and subsequently allowing the two cell types to interact and form connections.

Methods: Dopaminergic and neocortical progenitors were differentiated in separate vessels, then separately seeded into the inner and outer compartments of specialized cell culture vessels designed for in vitro studies of wound healing. Cells were further differentiated using dopamine-specific and neocortex-specific trophic factors, respectively. The barrier was then removed, and differentiation was continued for three weeks in the presence of BDNF.

Results: After three weeks of differentiation, neocortical and mDA cell bodies largely remained in the areas into which they had been seeded, and the gap between the mDA and neocortical neuron populations could still be discerned. Abundant tyrosine hydroxylase (TH)-positive projections had extended from the area of the inner chamber to the outer chamber neocortical area. Conclusions: We have developed a hPSC-based system for producing connections between neurons from two brain regions, neocortex and midbrain. Future experiments could employ modifications of this method to examine connections between any two brain regions or neuronal subtypes that can be produced from hPSCs in vitro.
\end{abstract}

Keywords: Neocortex, dopamine, human, pluripotent stem cell, differentiation, embryonic stem cell, neuronal projections

\section{Introduction}

Multiple methods exist for differentiating human embryonic stem cells (hESC; derived from blastocysts) or induced pluripotent stem cells (hiPSC; derived from human subjects) in vitro to produce neurons (Nelson et al., 2008; Reubinoff et al., 2001; Schultz et al., 2003; Zeng et al., 2010; Zhang et al., 2001). Specific individual neuronal cell types such as mDA neurons

\footnotetext{
${ }^{1}$ These authors contributed equally to this work.

${ }^{2}$ Current address: William J. Freed, Department of Biology, Lebanon Valley College, 101 College Avenue, Annville, PA, 17003. E-mail: freed@lvc.edu.

*Corresponding author: Dr. Chun-Ting Lee, NIDA Intramural Research Program, 333 Cassell Drive, Triad Bldg, Room 3305, Baltimore, MD 21224, USA. Tel.: +1 443740 2604; Fax: +1 443 740 2123; E-mail: clee@mail.nih.gov.
}

(Kriks et al., 2011; Perrier et al., 2004; Vazin et al., 2009; Yan et al., 2005; Zeng et al., 2004), and structures resembling the cerebral cortex (Eiraku et al., 2008; Kadoshima et al., 2013; Kindberg et al., 2014; Shi et al., 2012) can also be produced from hPSCs. Although various types of neurons can be separately produced in vitro, there is no available method for allowing two separately-differentiated types of neurons to form connections with each other.

Recently, a technique which allows more complex structures, i.e. "organoids", to be produced in vitro as models of the brain per se, including various types of neurons, has been described (Lancaster et al., 2013). This technique allows multiple types of neurons to form; however, since brain regionalization in these organoids is inconsistent, there are difficul- 
ties in using this model to examine specific neuronal pathways, or for quantitative studies that would be required for examining developmental toxicity or for pharmacological applications. At present, there are no well-established methods for modeling interconnections between brain regions, or between neurons of different types, using hPSCs. Furthermore, there is currently no method which allows for the production of two separate types of neurons or cells from hPSCs and subsequently allowing them to interact.

For the brain, as compared to most other organs, e.g. the liver, there are major limitations involved in examining a single neuronal cell type in isolation. Brain developmental and functional processes are highly dependent on interactions between different neural cell types and between different regions of the brain (for example, De Marco Garcia et al., 2011; Nishi, 2003). A great deal of attention has, for example, been focused on differentiation of human mDA neurons from hPSCs (Kriks et al., 2011; Perrier et al., 2004; Vazin et al., 2009; Yan et al., 2005; Zeng et al., 2004) because of their potential for use in transplantation therapy for Parkinson's disease. The development and formation of mDA neurons does not, however, occur in isolation, and DA systems and their targets structures are highly interdependent (Halliday et al., 2000; Hemmendinger et al., 1981; Hoffman et al., 1983; Parish et al., 2001; Prasad and Pasterkamp, 2009; Shalaby et al., 1984). Dopaminergic neurons are important for substance abuse (Volkow et al., 2004; Wise, 2013), for motivational processes in general (Wise, 2004), and in the pharmacotherapy of schizophrenia (Knable and Weinberger, 1997; Weinberger and Lipska, 1995). Both schizophrenia and substance abuse are believed to involve interactions between mDA neurons and target cells in the forebrain (Knable and Weinberger, 1997; Koob and Volkow, 2010; Weinberger and Lipska, 1995). Therefore, the possibilities for employing either mDA neurons or neocortical neurons derived from hPSCs in isolation to elucidate substance abuse or schizophrenia are very limited. The availability of an hPSC-based model which would allow for the examination of mDA-cortical interactions would substantially enhance such studies.

The purpose of the present proposal is to develop a system which allows multiple brain structures or neuronal subtypes to be produced, that is, differentiated, from a single population of hPSCs, and subsequently allowed to interact. This system was applied to the mDA projection to the neocortex, but also has the potential to be used for any two structures that can be differentiated from hPSCs.

\section{Methods}

\section{1. hPSC culture}

hESC lines ES04 (P65-69), provided by ES Cell International (Singapore), and CT2 (P88-90), provided by University of Connecticut Stem Cell Core, were propagated in feeder-dependent culture, using irradiated mouse embryonic fibroblasts (MEF, Global Stem). hESCs were cultured in hESC medium, containing DMEM/F12 with 20\% Knockout Serum Replacement (KSR), $2 \mathrm{mM}$ L-Glutamine, Pen/Strep (50 U/ml and $\mu \mathrm{g} / \mathrm{ml}$, respectively), $2 \mathrm{mM}$ nonessential amino acids, $0.1 \mathrm{mM} \beta$-mercaptoethanol, and $4 \mathrm{ng} / \mathrm{ml}$ bFGF (all from Invitrogen). Colonies were passaged using $1 \mathrm{mg} / \mathrm{ml}$ Collagenase Type IV (Invitrogen) every 5 days (1:3 split ratio). Cell karyotype analyses were routinely performed on twenty G-banded metaphase cells.

\subsection{Dopaminergic neuron differentiation}

hPSCs were differentiated to mDA neurons (Fig. 1A) using an adaptation of the method described by Yan et al. (2005). Briefly, undifferentiated hPSC colonies (day 0) were grown as floating EBs in hESC medium without bFGF for 4 days. On day 4 the floating EBs were transferred to neural media containing DMEM/F-12 (2:1) with N2 supplement, $0.1 \mathrm{mM}$ nonessential amino acids, $2 \mu \mathrm{g} / \mathrm{ml}$ heparin, supplemented with $20 \mathrm{ng} / \mathrm{ml}$ bFGF (Invitrogen) from days 4-6, and were then grown in adherent culture in same media from days 6-10. On day 10 , bFGF was replaced with $50 \mathrm{ng} / \mathrm{ml}$ FGF8 (R\&D), and the cells were maintained in this medium until day 16 . On day 16 , neural rosettes were isolated by manual dissection and grown as floating $\mathrm{NE}$ aggregates in neural medium supplemented with $50 \mathrm{ng} / \mathrm{ml} \mathrm{FGF8} \mathrm{for} 2$ days, followed by addition of $50 \mathrm{ng} / \mathrm{ml} \mathrm{FGF8}$ and $200 \mathrm{ng} / \mathrm{ml} \mathrm{SHH}$ (R\&D) from days 18-24. On day 24, NE aggregates were seeded on polyornithine/laminin-coated inner compartments of ibidi chambers and maintained in neurobasal medium containing $\mathrm{N} 2$ supplement, $0.1 \mathrm{mM}$ non-essential amino acids, $0.5 \mathrm{mM}$ L-Glutamine, $2 \mu \mathrm{g} / \mathrm{ml}$ heparin, $1 \mu \mathrm{M}$ cAMP, $1 \mu \mathrm{g} / \mathrm{ml}$ laminin, and $200 \mu \mathrm{M}$ ascorbic acid and supplemented with FGF8 (50 ng/ml), SHH (200 ng/ml, 
R\&D), BDNF (10 ng/ml, R\&D), and GDNF (10 ng/ml, R\&D) until removal of the barrier on day 31 of differentiation.

\subsection{Neocortical neuron differentiation}

Neocortical differentiation was performed according to the protocol illustrated in Fig. 1B, essentially as described by Kindberg et al. (2014) except that cells were dissociated on day 19, and at that time the ROCK inhibitor Y-27632 was added to the cultures. In brief, hPSC colonies were grown in non-adherent conditions in hESC medium without bFGF for four days, allowing EB formation. The EBs were then transferred to neural media containing DMEM/F-12 (2:1) with N2 supplement, $0.1 \mathrm{mM}$ non-essential amino acids, and $2 \mu \mathrm{g} / \mathrm{ml}$ heparin, supplemented with $20 \mathrm{ng} / \mathrm{ml} \mathrm{bFGF}$ for two additional days (day 6). Colonies were then grown in adherent culture, on laminin-coated plates, in the same media with $20 \mathrm{ng} / \mathrm{ml}$ bFGF from days 6 to 16. On day 16 dorsal cortical rosettes were isolated by manual dissection, dissociated into 50-100 $\mu \mathrm{m}$ diameter colonies, and maintained in suspended culture in the same medium with $20 \mathrm{ng} / \mathrm{ml} \mathrm{bFGF}$ before being seeded on poly-ornithine/laminin coated dishes at day 19. On day 19 , colonies were dissociated using accutase for 20 minutes at $37^{\circ} \mathrm{C}$, washed using neural media, and placed into the outer area of the ibidi chambers in neurobasal medium containing B27 supplement, $0.1 \mathrm{mM}$ non-essential amino acids, $0.5 \mathrm{mM}$ L-Glutamine, and $2 \mu \mathrm{g} / \mathrm{ml}$ heparin but with the addition of FGF18 ( $20 \mathrm{ng} / \mathrm{mL}$, Biosource), NT3 (20 ng/mL, R\&D), BDNF ( $20 \mathrm{ng} / \mathrm{mL}, \mathrm{R} \& \mathrm{D})$ and the ROCK inhibitor Y-27632 (10 $\mu \mathrm{M}$, Stemgent) until the barrier was removed on day 26 of differentiation.

\subsection{Connection formation}

Connections between the mDA and neocorticallydifferentiated components were accomplished using the ibidi wound healing dish (ibidi GmbH, Planegg, Germany) (http://ibidi.com/xtproducts/en/ibidi-Lab ware/Open-Slides-Dishes:-Removable-Chambers/Cul ture-Insert-Family). Of various possible vessels that might be used for this technique, the ibidi dishes provide the best alternative that we have examined. These dishes are optimized for studies of wound healing, using dissociated keratinocytes or fibroblasts. The day at which the barrier between the inner and outer chambers was removed was day 31 for
mDA differentiation, and day 26 for neocortical differentiation, as indicated in Fig. $1 \mathrm{~A}-\mathrm{C}$. On the day of barrier removal, the medium was changed and replaced with neurobasal medium containing B27 supplement, $0.1 \mathrm{mM}$ non-essential amino acids, $0.5 \mathrm{mM}$ L-Glutamine, and $2 \mu \mathrm{g} / \mathrm{ml}$ heparin, containing $20 \mathrm{ng} / \mathrm{ml} \mathrm{BDNF}$, and no other trophic factors.

\subsection{Immunocytochemistry}

Cells were fixed with $4 \%$ PFA for $10 \mathrm{~min}$, washed with PBS, and blocked with $0.2 \%$ Triton $\mathrm{X}$ in PBS supplemented with 5\% BSA and $10 \%$ goat/donkey serum. Cells were then incubated with primary antibodies in $0.2 \%$ Triton $\mathrm{X}$ in PBS with $5 \%$ BSA and $5 \%$ goat/donkey serum: rabbit anti-LMX1A $(1: 2,000$, Millipore), goat anti-FOXA2 (1:50; Santa Cruz), rabbit anti-TH (1:500; Pel-Freez), mouse anti-TUJ1 (1:2,000; Promega), rabbit anti-TUJ1 (1:2,000; Covance), rabbit anti-OTX2 (1:1000; Millipore), mouse anti-Nestin (1:50; R\&D), rabbit anti-BF1 (1:100; Abcam), mouse anti- NKX2.1 (1:200; Chemicon), rabbit anti-PAX6 (1:300; Covance), rabbit anti-Glutamate (1:2000; Sigma), rabbit anti-VGLUT1 (1:500; Synaptic Systems), rabbit anti-VGLUT2 (1:500; Synaptic Systems), mouse anti-GABA (1:100, Sigma), and rabbit anti-VGAT (1:500; Synaptic Systems).

Corresponding fluorescent-labeled secondary antibodies were used (Alexa-Fluor 488 for green, Alexa-Fluor 555 for red; R\&D). Images were captured using a Carl Zeiss Axiovert 200M (Jena, Germany) microscope.

\subsection{AAV viral transduction}

The construction of pdsAAVGFP has been described previously (Wang et al., 2003). Vectors were packaged based on the triple transfection method (Xiao et al., 1998) as previously described (Howard et al., 2008). To provide the rep/cap genes for producing serotypes 2 and 6, pXX2 (Xiao et al., 1998) and pAAV2/6 (Rabinowitz et al., 2002) were used respectively. Both AAV2 and AAV6 were purified by $\mathrm{CsCl}$ ultracentrifugation and titered using real-time PCR as previously described (Howard et al., 2008). A multiplicity of infection of 10,000 to 20,000 was used for transduction. The transduction efficiency was more than $80 \%$ as assessed by microscopic observation. 

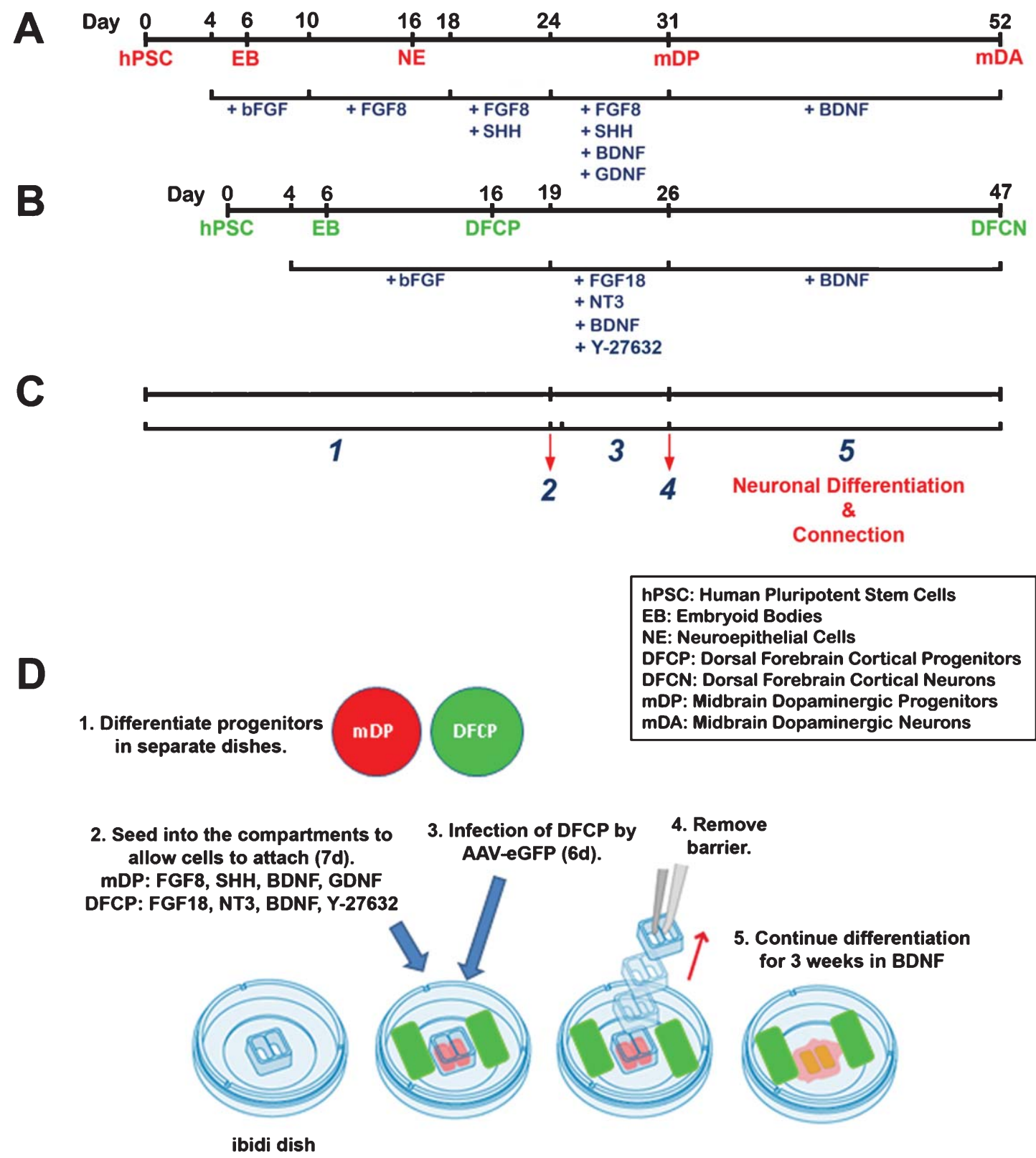

Fig. 1. Illustration of the differentiation and connection protocol. (A) Protocol for induction of the mesencephalic dopaminergic component, adapted from the method described by Yan et al. (2005). The upper line indicates days of differentiation, beginning with day 0 , the final day at which hPSCs were maintained in undifferentiated growth conditions. Abbreviations in red (defined in the boxed insert) below the upper line indicate differentiation stages. The lower line indicates the trophic factors (blue) which were added at each stage. (B) Protocol for induction of neocortical differentiation, based on the method of Kindberg et al. (2014). Abbreviations in green indicate differentiation stages and the trophic factors added are indicated in blue below the lower line. (C and D) Stages of the neuronal subtype interconnection model; numbers in italics below $\mathrm{C}$ correspond to the stages illustrated in D. 1: Progenitors are differentiated in separate plates. 2: Progenitors are seeded into separate compartments of ibidi dishes. 3: Infection by AAV-eGFP; or other manipulations of each separate cell type can be performed while the cell types remain in separate compartments, treated with different combinations of trophic factors. 4: The barrier between cell types is removed. 5: Neuronal differentiation is allowed to continue for 3 weeks, with both cells types exposed to the same media containing BDNF only. 


\section{Results}

\section{1. mDA differentiation}

For differentiation of mDA cells from hPSCs as illustrated in Fig. 1A, colonies of mDA progenitor cells at day 31 expressed the mDA transcription factors LMX1A and FOXA2 (Fig. 2A). When allowed to differentiate for 52 days (Fig. 1A), in neurobasal medium with B27 supplement including BDNF as the only added trophic factor from days 31-52, the colonies contained numerous $\mathrm{TH}^{+}$and $\mathrm{TUJ}^{+}$neurons (Fig. 2B, C). The colonies remained largely intact, with clusters of $\mathrm{TH}^{+}$fiber projections present at day 52 (Fig. 2B). At day 52, $\mathrm{TH}^{+}$neurons comprised approximately one third of the total TUJ1 + cells (Fig. 2C).

\subsection{Neocortical differentiation}

For differentiation of neocortical neurons from hPSCs, as illustrated in Fig. 1B Nestin ${ }^{+}$neuroepithelial rosettes expressed the anterior telencephalic
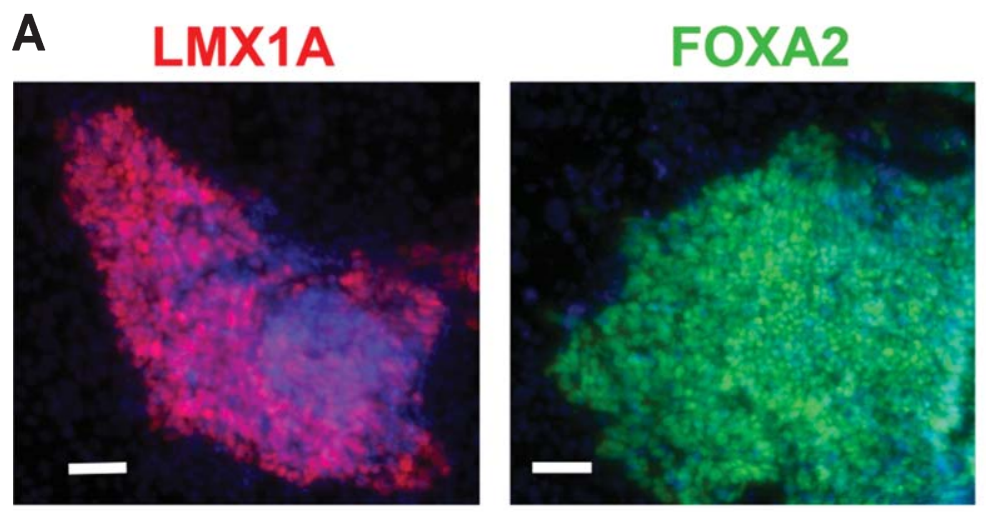
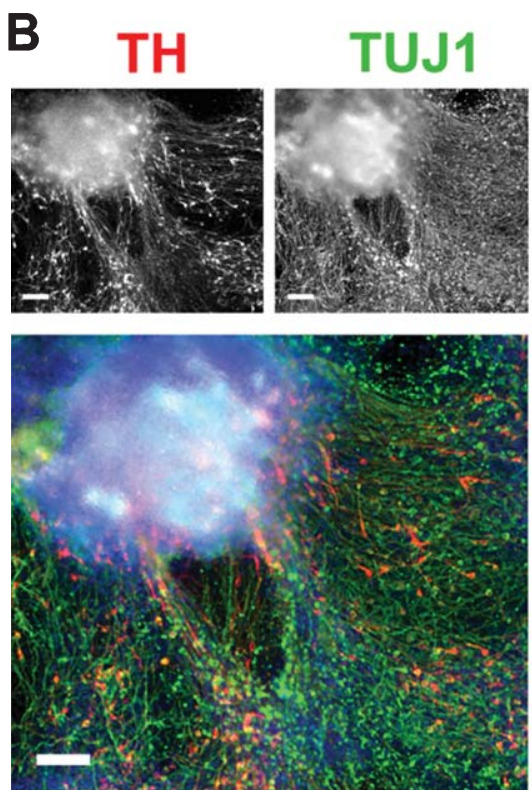

TUJ1
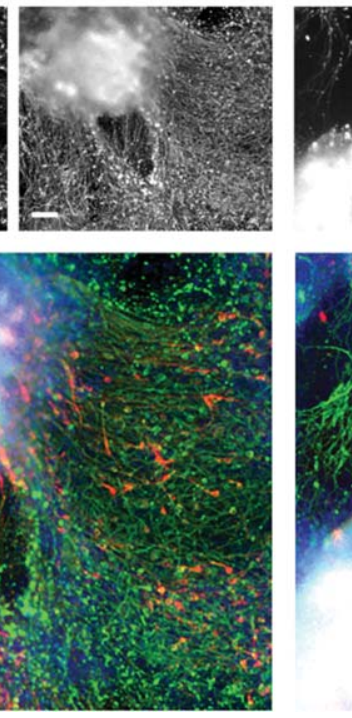
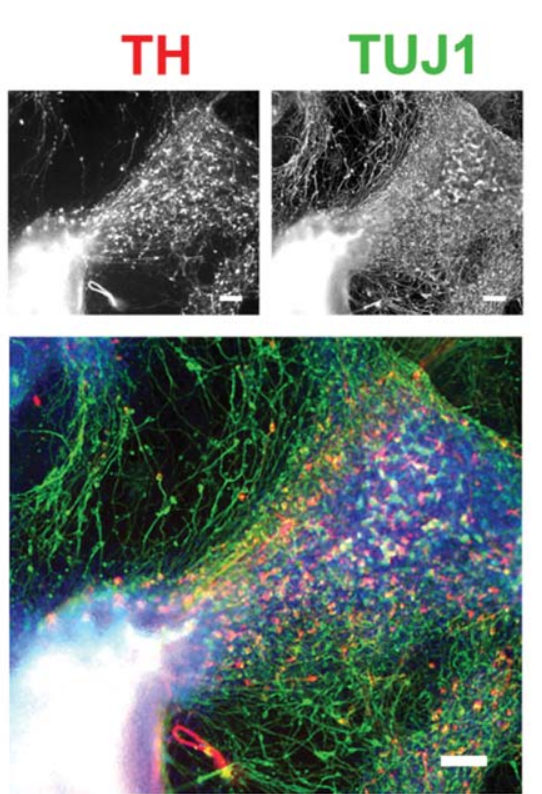

C
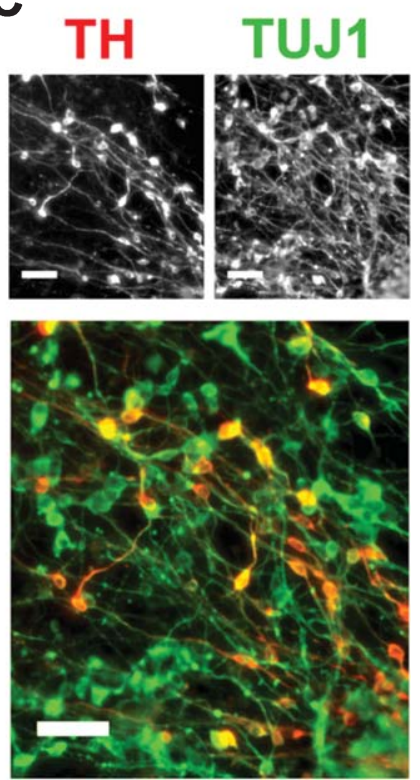

Fig. 2. Dopaminergic differentiation. (A) Expression of LMX1A and FOXA2, transcription factors for mesencephalic DA progenitor cells, at day 31, prior to removal of the barrier between cell types. Scale bar $=50 \mu \mathrm{m}$. (B) Expression of TH (red) and TUJ1 (green) by immunocytochemistry at day 52, for mDA neurons differentiated according to the protocol, as shown in Fig. 1A, showing projections extending from colonies positive for $\mathrm{TH}$ and TUJ1. Scale bar $=100 \mu \mathrm{m}$. (C) Higher magnification image of mDA neurons differentiated for 52 days showing individual TH-positive (red) and TUJ1-positive (green) neurons. Scale bar $=50 \mu \mathrm{m}$. Cell line: ES04. 
transcription factors OTX2 and BF1 (Li et al., 2009), and the dorsal forebrain marker PAX6 (Manuel et al., 2005), but did not express the ventral telencephalic marker NKX2.1 (Fig. 3A). At the end of differentiation, on day 47 for neocortical differentiation, the majority of $\mathrm{TUJ}^{+}$neurons had adopted a glutamatergic phenotype (Fig. 3B), expressing the vesicular glutamate transporters VGLUT1 and VGLUT2 (Fig. 3C). On day 47 the differentiated population also included a small population of GABA-containing neurons (Fig. 3D) expressing VGAT (Fig. 3E).

\subsection{Connection formation}

To build connections between $\mathrm{mDA}$ and neocortical neurons as described in Fig. 1C, D, the general distribution of progenitors within the inner and outer chambers is illustrated by the cartoon Fig. 4A. The appearance of the gap between the inner and outer chambers is shown in Fig. 4B. After the progenitors were seeded into ibidi chambers on day 24 of mDA differentiation and day 19 of neocortical differentiation, each type of progenitors was further differentiated using mDAspecific and neocortex-specific trophic factors for 1 week. After the barrier was removed, neuronal differentiation was continued for an additional 3 weeks using the same culture conditions for both neuronal subtypes, neurobasal medium with B27 supplement containing $20 \mathrm{ng} / \mathrm{mL}$ BDNF, but with no other trophic factors. At the end of differentiation, neurons retained their phenotypic identity and largely remained in their respective locations on each side of the barrier with few cells having migrated across the gap between the chambers, to the other side (Fig. 4C-E). As can be seen in Fig. 4C the gap between the two different neuronal populations narrowed over time, and some cells had moved into the area vacated by the barrier.

Neocortical progenitors were infected using both AAV2- and AAV6-eGFP for 6 days, and $\sim 80 \%$ of neocortical neurons were positive for GFP at the end of differentiation (Fig. 1C, D; Fig. 4D, E). Immunostaining and fluorescence imaging showed that a few $\mathrm{GFP}^{+}$neocortical cells had migrated into the area of mDAergic $\mathrm{TH}^{+}$neurons, while conversely a few $\mathrm{TH}^{+}$ cells were seen in the area of the outer chamber, among the $\mathrm{GFP}^{+}$neocortical neurons. Nonetheless, the majority of cells remained in the areas of the inner and outer chambers respectively. In areas where groups of $\mathrm{TH}^{+}$neurons were in proximity to $\mathrm{GFP}^{+}$neocortical neurons, $\mathrm{TH}^{+}$projections were seen to have extended outward from the DA neurons, crossing the gap and extending into the area of neocortical neurons (Fig. 4D). In some cases the $\mathrm{TH}^{+}$neurons had elaborated processes which had the appearance of terminal arborization (Fig. 4E, lower left), resembling that which is seen in DA target areas of the rat brain (e.g., Matsuda et al., 2009).

\section{Discussion}

We have succeeded in arranging differentiation, plating, and trophic factor conditions which allow mDA and neocortical neurons to be differentiated from $\mathrm{hPSC}$ and form connections in vitro. Although many previous methods allow hPSCs to be induced to differentiate into multiple types of neurons, it has not been possible to produce two different kinds of neurons in the same culture vessel, because within one culture vessel different trophic factors cannot be separately applied to each neuronal progenitor population. If neuronal progenitors of different types are terminally differentiated in separate vessels, the differentiated neurons are not amenable to removal and transfer from one vessel to a separate location to allow the neurons to interact. There are various types of culture vessels which allow trophic factors to be applied to different sub-groups of cells, such as chamber slides, or "sticky" inserts, but these methods are not useful in the present situation for various reasons, such as a wide gap between the cell populations or the complications involved in transferring an entire chamber slide to a larger vessel. If, however, the two separate cell types are differentiated using the ibidi wound-healing dish, the interaction problem can be solved by removal of the cell barrier at an appropriate stage.

Many types of studies related to disorders including drug abuse, schizophrenia, Parkinson's disease, and perhaps eating disorders, attention deficithyperactivity disorder, Tourette's syndrome, and Lesch-Nyhan syndrome, which may involve dopaminergic systems (Iversen et al., 2009) could be enhanced through this use of this model, as compared to the use of mDA neurons in isolation. For example, hPSCderived mDA neurons have been used as a model of $\mathrm{MPP}+$ toxicity and GDNF protection (Zeng et al., 2006), but MPP+ toxicity is known to involve the fine terminal arborization of $\mathrm{mDA}$ terminals in the 


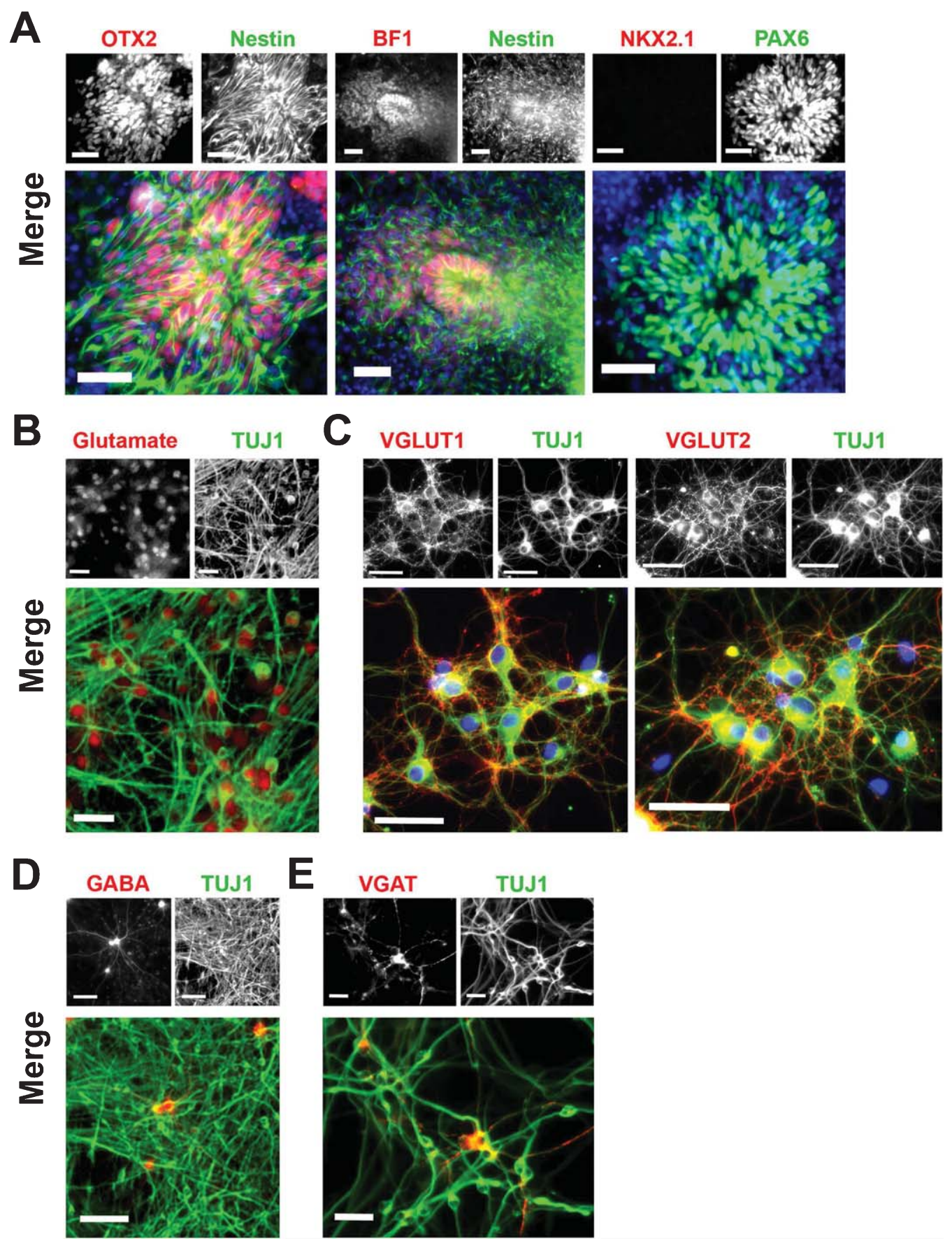

Fig. 3. Neocortical differentiation. (A) Characterization of neocortical neuroepithelial rosettes derived from hPSCs on day 16 of differentiation. $\mathrm{Nestin}^{+}$rosettes (green) contain cells expressing the anterior telencephalic transcription factors OTX2 (red, left frame), BF1 (red, middle frame), and PAX6 (green, right frame). In contrast, the ventral telencephalic marker NKK2.1 (red, right frame) was not expressed. Nuclei are stained with DAPI (blue). Scale bar $=50 \mu \mathrm{m}$. (B) Immunocytochemical staining for glutamate (red) and TUJ1 (green) on day 47 of differentiation using the current protocol, as shown in Fig. 1B. Scale bar $=25 \mu \mathrm{m}$. (C) TUJ1 ${ }^{+}$neurons (green) were positive for the vesicular glutamate transporters VGLUT1 (red, left frame) and VGLUT2 (red, right frame) on day 47 of differentiation. Nuclei are stained with DAPI (blue). Scale bar $=50 \mu \mathrm{m}$. (D) Expression of GABA (red) and TUJ1 (green) by immunocytochemistry on day 47 of differentiation. Scale bar $=100 \mu \mathrm{m}$. (E) Expression of the GABA transporter VGAT (red) and TUJ1 (green) by immunocytochemistry on day 47 of differentiation. Scale bar $=25 \mu \mathrm{m}$. Cell line: ES04. 
A

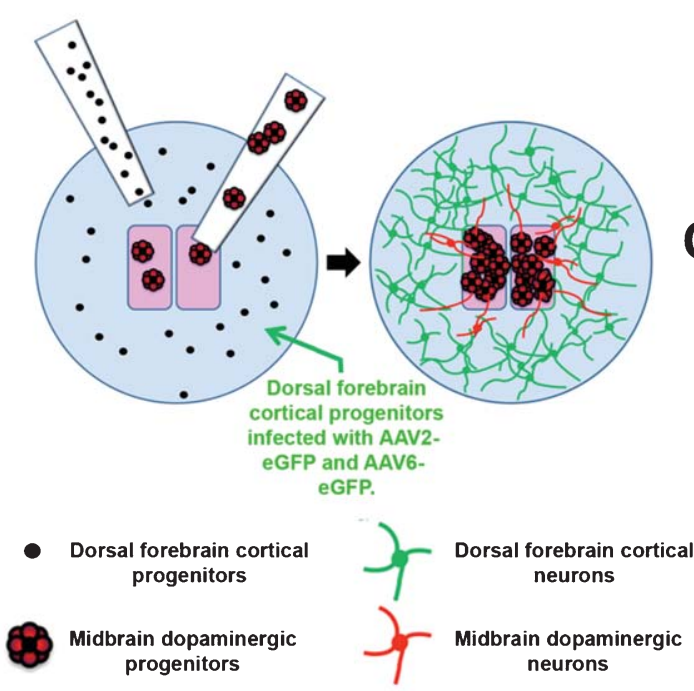

D

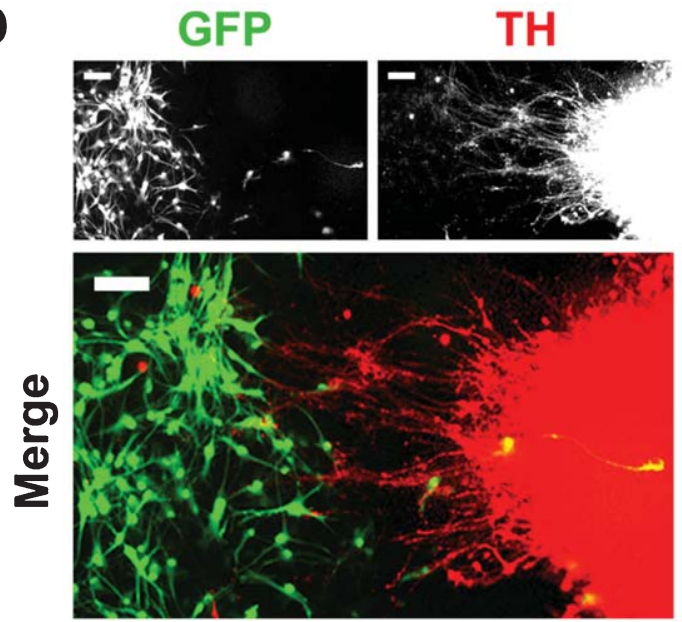

B

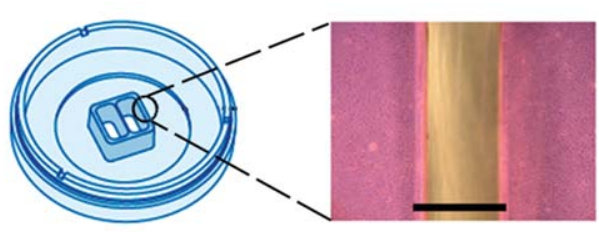

C

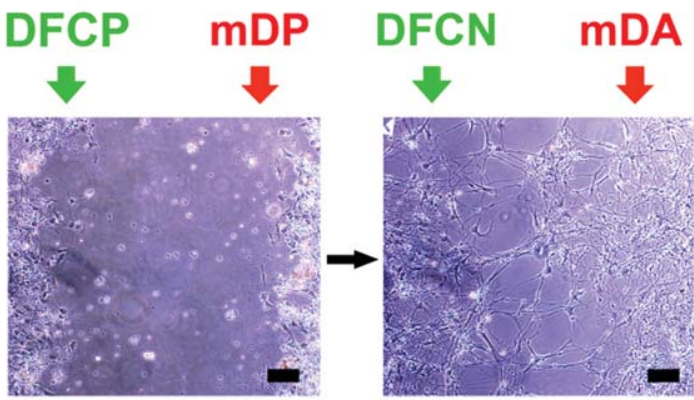

Day 1

Day 21

E

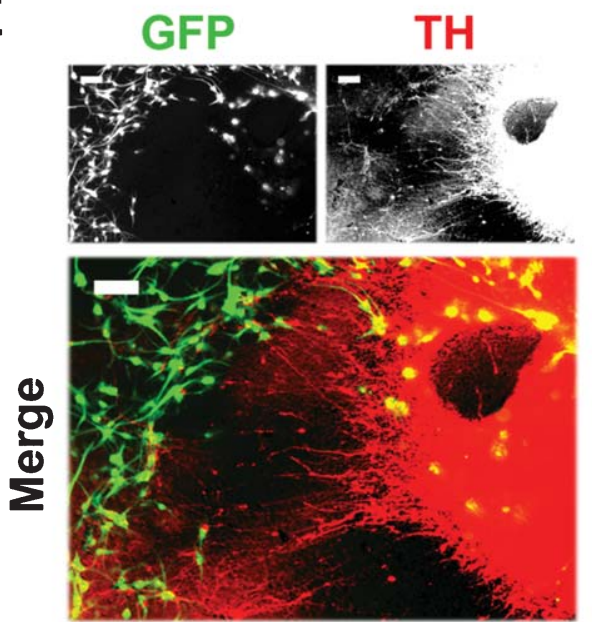

Fig. 4. Development of projections between neocortical and DA neurons. (A) Illustration of the process of progenitor seeding into separate chambers, and development of connections after removal of the barrier between chambers. (B) Illustration of the gap between chambers after removal of the barrier (courtesy of ibidi GmbH, Planegg, Germany). Phase contrast image, scale bar $=500 \mu \mathrm{m}$. (C) Phase contrast images of the gap between the inner and outer chambers on day 1 after removal of the barrier and after 21 days. Note that the gap between DA and neocortical neurons persists on day 21 although some cells and projections are seen between the two regions. Scale bar $=100 \mu \mathrm{m}$. (D) An example of TH-positive projections (red) from the inner chamber to the area of the outer chamber after 21 days. Scale bar $=100 \mu \mathrm{m}$. (E) An example of TH-positive projection forming a fine terminal aborization among $\mathrm{GFP}^{+}$neocortical cells, seen in the lower left of the merged image. Scale $\mathrm{bar}=100 \mu \mathrm{m}$. Neocortical neurons were labelled with AAV-eGFP (green). Note that some eGFP-positive cells have migrated across the gap, to the inner area, and are interspersed with TH-positive neurons. These cells appear yellow in these images. Cell line: CT2.

striatum, which occur only in the presence of appropriate synaptic targets of $\mathrm{mDA}$ neurons as well (Feuerstetin et al., 1988), and thus such studies might be enhanced. Co-cultures of mDA neurons and striatal neurons for use in studies of MPP+ toxicity can be created from rodent fetal material (Koutsilieri et al.,
1993), but this allows for similar studies using human material.

Among various available types of culture vessels and materials that might be adapted for this purpose, the ibidi wound-healing dish is the best alternative that we have found. Notwithstanding the favorable properties 
of this type of dish, we believe that the principal limitation is the small size of the surface available for these cultures. Thus, when mDA progenitor colonies are placed into the wells, they do not distribute uniformly, and the size of the chambers is too small to allow for consistent sampling. Since the mDA progenitors used in this study do not form projections well if entirely dissociated, the cells cannot be smoothly distributed within the small area available using the present technique. There are various other geometries of this kind of dish which might be envisioned to further improve the outcome, or to facilitate quantification. Nonetheless, even with the available geometry of the ibidi dishes, the present technique allows two different types of neurons to be separately induced from hPSCs, and subsequently allowed to interact. This method, therefore, has the potential to expand the potential of hPSC-derived neurons to allow for studies of human neural systems and interconnections that have previously not been possible to model in vitro.

\section{Acknowledgments}

Research supported by the IRP of NIDA, NIH. We thank Brandon K. Harvey and the Optogenetics and Transgenic Technology Core, IRP, NIDA, NIH, for providing the AAV-eGFP vector, Ora Dillon-Carter for helpful suggestions regarding cell culture techniques, and Cindy Ambriz for assistance in preparing the manuscript.

\section{References}

De Marco García, N.V., Karayannis, T., \& Fishell, G. (2011). Neuronal activity is required for the development of specific cortical interneuron subtypes. Nature, 472, 351-355.

Eiraku, M., Watanabe, K., Matsuo-Takasaki, M., Kawada, M., Yonemura, S., Matsumura, M., Wataya, T., Nishiyama, A., Muguruma, K., \& Sasai, Y. (2008). Self-organized formation of polarized cortical tissues from ESCs and its active manipulation by extrinsic signals. Cell Stem Cell, 3, 519-532.

Feuerstein, T.J., Hedler, L., Jackisch, R., \& Hertting, G. (1988). An in vitro model of 1-methyl-4-phenyl-pyridinium (MPP+) toxicity: Incubation of rabbit caudate nucleus slices with MPP+ followed by biochemical and functional analysis. Br J Pharmacol, 95, 449-458.

Halladay, A.K., Yue, Y., Michna, L., Widmer, D.A., Wagner, G.C., \& Zhou, R. (2000). Regulation of EphB1 expression by dopamine signaling. Brain Res Mol Brain Res, 85, 171-178.

Hemmendinger, L.M., Garber, B.B., Hoffmann, P.C., \& Heller, A. (1981). Target neuron-specific process formation by embryonic mesencephalic dopamine neurons in vitro. Proc Natl Acad Sci USA, 2, 1264-1268.

Hoffmann, P.C., Hemmendinger, L.M., Kotake, C., \& Heller, A. (1983). Enhanced dopamine cell survival in reaggregates containing telencephalic target cells. Brain Res, 274, 275-281.

Howard, D.B., Powers, K., Wang, Y., \& Harvey, B.K. (2008). Tropism and toxicity of adeno-associated viral vector serotypes $1,2,5,6,7,8$, and 9 in rat neurons and glia in vitro. Virology, $372,24-34$.

Iversen, L., Iversen, S., Dunnett, S.B. \& Bjorklund, A. (2009). Dopamine Handbook, Oxford University Press.

Kadoshima, T., Sakaguchi, H., Nakano, T., Soen, M., Ando, S., Eiraku, M., \& Sasai, Y. (2013). Self-organization of axial polarity, inside-out layer pattern, and species-specific progenitor dynamics in human ES cell-derived neocortex. PNAS, 110, 20284-20289.

Kindberg, A.A., Bendriem, R.M., Spivak, C.E., Chen, J., Handreck, A., Lupica, C.R., Liu, J., Freed, W.J., \& Lee, C.T. (2014). An in vitro model of human neocortical development using pluripotent stem cells: Cocaine-induced cytoarchitectural alterations. Dis Model Mech, 7(12), 1397-1405.

Koob, G.F., \& Volkow N.D. (2010). Neurocircuitry of addiction. Neuropsychopharmacology, 35, 217-238.

Koutsilieri, E., Chan, W.W., Reinitzer, D., \& Rausch, W.D. (1993). Functional changes in cocultures of mesencephalon and striatal neurons from embryonic C57/BL6 mice due to low concentrations of 1-methyl-4-phenylpyridinium (MPP+). J Neural Transm Gen Sect, 94, 189-197.

Knable, M.B., \& Weinberger, D.R. (1997). Dopamine, the prefrontal cortex and schizophrenia. J Psychopharmacol, 11, 123-131.

Kriks, S., Shim, J.W., Piao, J., Ganat, Y.M., Wakeman, D.R., Xie, Z., Carrillo-Reid, L., Auyeung, G., Antonacci, C., Buch, A., Yang, L., Beal, M.F., Surmeier, D.J., Kordower, J.H., Tabar, V., \& Studer, L. (2011). Dopamine neurons derived from human ES cells efficiently engraft in animal models of Parkinson's disease. Nature, 480, 547-551.

Lancaster, M.A., Renner, M., Martin, C.A., Wenzel, D., Bicknell, L.S., Hurles, M.E., Homfray, T., Penninger, J.M., Jackson, A.P., \& Knoblich, J.A. (2013). Cerebral organoids model human brain development and microcephaly. Nature, 501, 373-379.

Li, X.J., Zhang, X., Johnson, M.A., Wang, Z.B., Lavaute, T. \& Zhang, S.C. (2009). Coordination of sonic hedgehog and Wnt signaling determines ventral and dorsal telencephalic neuron types from human embryonic stem cells. Development, 136, 4055-4063.

Manuel, M. \& Price, D.J. (2005). Role of Pax6 in forebrain regionalization. Brain Res Bull, 66, 387-393.

Matsuda, W., Furuta, T., Nakamura, K.C., Hioki, H., Fujiyama, F., Arai, R., \& Kaneko, T. (2009). Single nigrostriatal dopaminergic neurons form widely spread and highly dense axonal arborizations in the neostriatum. J Neurosci, 29, 444-453.

Nelson, A.D., Suzuki, M., \& Svendsen, C.N. (2008). A high concentration of epidermal growth factor increases the growth and survival of neurogenic radial glial cells within human neurosphere cultures. Stem Cells, 26, 348-355.

Nishi R. (2003). Target-mediated control of neural differentiation. Prog Neurobiol, 69, 213-227. 
Parish, C.L., Finkelstein, D.I., Drago, J., Borrelli, E., \& Horne, M.K. (2001). The role of dopamine receptors in regulating the size of axonal arbors. J Neurosci, 21, 5147-5157.

Perrier, A.L., Tabar, V., Barberi, T., Rubio, M.E., Bruses, J., Topf, N., Harrison, N.L., \& Studer, L. (2004). Derivation of midbrain dopamine neurons from human embryonic stem cells. Proc Natl Acad Sci USA, 101, 12543-12548.

Prasad, A.A., \& Pasterkamp, R.J. (2009). Axon guidance in the dopamine system. Adv Exp Med Biol, 651, 91-100.

Rabinowitz, J.E., Rolling, F., Li, C.W., Conrath, H., Xiao, W.D., Xiao, X., \& Samulski, R.J. (2002). Cross-packaging of a single adeno-associated virus (AAV) type 2 vector genome into multiple AAV serotypes enables transduction with broad specificity. J Virology, 76, 791-801.

Reubinoff, B.E., Itsykson, P., Turetsky, T., Pera, M.F., Reinhartz, E., Itzik, A., \& Ben-Hur, T. (2001). Neural progenitors from human embryonic stem cells. Nat Biotechnol, 19, 1134-1140.

Schulz, T.C., Palmarini, G.M., Noggle, S.A., Weiler, D.A., Mitalipova, M.M., \& Condie, B.G. (2003). Directed neuronal differentiation of human embryonic stem cells. BMC Neurosci, $4,27$.

Shalaby, I.A., Hoffmann, P.C., \& Heller, A. (1984). Release of dopamine from mesencephalic neurons in aggregate cultures: Influence of target and non-target cells. Brain Res, 307, 347350 .

Shi, Y., Kirwan, P., Smith, J., Robinson, H.P., \& Livesey, F.J. (2012). Human cerebral cortex development from pluripotent stem cells to functional excitatory synapses. Nature Neurosci, 15, 477 486.

Vazin, T., Becker, K.G., Chen, J., Spivak, C.E., Lupica, C.R., Zhang, Y., Worden, L., \& Freed, W.J. (2009). A novel combination of factors, termed SPIE, which promotes dopaminergic neuron differentiation from human embryonic stem cells. PLoS One, 4, e6606.

Volkow, N.D., Fowler, J.S., Wang, G.J., \& Swanson, J.M. (2004). Dopamine in drug abuse and addiction: Results from imaging studies and treatment implications. Mol Psychiatry, 9, 557-569.
Wang, Z., Ma, H.I., Li J., Sun, L., Zhang, J., \& Xiao, X. (2003). Rapid and highly efficient transduction by double-stranded adenoassociated virus vectors in vitro and in vivo. Gene Ther, 10, 2105-2111.

Weinberger, D.R., \& Lipska, B.K. (1995) Cortical maldevelopment, anti-psychotic drugs, and schizophrenia: A search for common ground. Schizophr Res, 16, 87-110.

Wise, R.A. (2004). Dopamine, learning and motivation. Nat Rev Neurosci, 5, 483-494.

Wise, R.A. (2013). Dual roles of dopamine in food and drug seeking: The drive-reward paradox. Biol Psychiatry, 73, 819-826.

Xiao, X., Li J., \& Samulski, R.J. (1998). Production of high-titer recombinant adeno-associated virus vectors in the absence of helper adenovirus. $J$ Virol, 72, 2224-2232.

Yan, Y., Yang, D., Zarnowska, E.D., Du, Z., Werbel, B., Valliere, C., Pearce, R.A., Thomson, J.A., \& Zhang S.C. (2005). Directed differentiation of dopaminergic neuronal subtypes from human embryonic stem cells. Stem Cells, 23, 781-790.

Zeng, H., Guo, M., Martins-Taylor, K., Wang, X., Zhang, Z., Park, J.W., Zhan, S., Kronenberg, M.S., Lichtler, A., Liu, H.X., Chen, F.P., Yue, L., Li, X.J., \& Xu, R.H. (2010). Specification of region-specific neurons including forebrain glutamatergic neurons from human induced pluripotent stem cells. PLoS One, 5, e11853.

Zeng, X., Cai, J., Chen, J., Luo, Y., You, Z.B., Fotter, E., Wang, Y., Harvey, B., Miura, T., Backman C., Chen, G.J., Rao, M.S., \& Freed W.J. (2004). Dopaminergic differentiation of human embryonic stem cells. Stem Cells, 22, 925-940.

Zeng, X., Chen, J., Deng, X., Liu, Y., Rao, M.S., Cadet, J.L., \& Freed, W.J. (2006). An in vitro model of human dopaminergic neurons derived from embryonic stem cells: MPP+ toxicity and GDNF neuroprotection. Neuropsychopharmacology, 31, 2708-2715.

Zhang, S.C., Wernig, M., Duncan, I.D., Brüstle, O., \& Thomson, J.A. (2001). In vitro differentiation of transplantable neural precursors from human embryonic stem cells. Nature Biotechnol, 19, 1129-1133. 